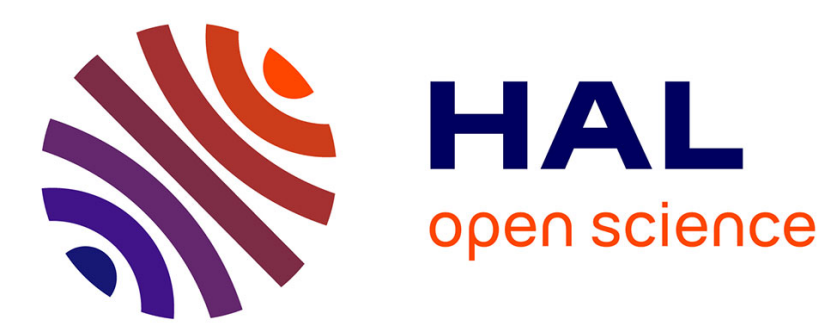

\title{
Time dependence of colour-temperature characteristics of liquid-crystalline thermoindicators
}

\author{
G.M. Zharkova, V.M. Kachaturyan
}

\section{To cite this version:}

G.M. Zharkova, V.M. Kachaturyan. Time dependence of colour-temperature characteristics of liquid-crystalline thermoindicators. Revue de Physique Appliquée, 1979, 14 (4), pp.555-558. 10.1051/rphysap:01979001404055500 . jpa-00244628

\section{HAL Id: jpa-00244628 \\ https://hal.science/jpa-00244628}

Submitted on 1 Jan 1979

HAL is a multi-disciplinary open access archive for the deposit and dissemination of scientific research documents, whether they are published or not. The documents may come from teaching and research institutions in France or abroad, or from public or private research centers.
L'archive ouverte pluridisciplinaire HAL, est destinée au dépôt et à la diffusion de documents scientifiques de niveau recherche, publiés ou non, émanant des établissements d'enseignement et de recherche français ou étrangers, des laboratoires publics ou privés. 


\title{
Time dependence of colour-temperature characteristics of liquid-crystalline thermoindicators
}

\author{
G. M. Zharkova and V. M. Kachaturyan \\ Institute of Theoretical and Applied Mechanics, \\ USSR Academy of Sciences, Novosibirsk 630090, U.S.S.R.
}

(Reçu le 10 août 1978, révisé le 18 décembre 1978, accepté le 4 janvier 1979)

\begin{abstract}
Résumé. - On a étudié des dépendances de température et de temps de la longueur d'onde de diffusion sélective de la lumière des cristaux cholestériques liquides, dispersés dans de différents polymères. On a mis en évidence que la stabilité des cristaux liquides est définie par l'étanchéité aux gaz des polymères. L'introduction simultanée des antioxydants dans le polymère augmente considérablement la durée de la vie des cristaux liquides.
\end{abstract}

\begin{abstract}
The temperature and time dependencies of the wavelength of selective light scattering of cholesteric liquid crystals dispersed in various polymers are studied. The stability of liquid crystals is found to be determined by the gas permeability of polymers. The injection of the antioxidants into the polymer increases essentially the lifetime of the capsulated liquid crystals.
\end{abstract}

1. Introduction. - The application of cholesteric liquid crystals (ChLC) for measuring the temperature in various fields of science and engineering necessitates an unceasing improvement of their operation characteristics. The instability of the thermoindicator properties in time $[1,2]$ has proved to be one of the shortcomings of thermoindicators operating on the basis of ChLC. Under the influence of air oxygen and ultraviolet radiation there occur irreversible oxidation processes in ChLC. This induces certain changes in their optical properties : the intensity and the temperature of selective light scattering.

A strong change of the scattered light intensity is associated with the texture changes. The intensity of the selectively scattered light is maximum in the case when ChLC forms a plane texture. The plane texture is formed by the mechanical shift of the molten ChLC (by means of a brush or a shear of the coating glass). In this layer the axis of the cholesteric spiral is placed normally to the substrate. With time such a texture is distroyed, and the ChLC layer loses its ability to scatter the light selectively.

The texture ageing is initiated both by the purely chemical changes proceeding in the substance and by the external factors : physical separation of components in the complex mixtures, influence of the substrate material, atmospheric dust.

There exist several means of stabilizing the liquidcrystalline thermoindicators : synthesis of new compounds and application of especially pure liquidcrystalline substances, injection of antioxidants and photoantioxidants into thermoindicators, microcapsulation of liquid crystals.

Nowadays the thermoindicator films containing ChLC in the form of capsules uniformely distributed in a polymer $[3,4]$ are finding ever wider application. Since the conditions under which the thermoindicator films are used may be different, extra requirements are made to the polymer : it should be stable to water or organic solvents. Both the utilization of waterrepellent polymers and that of water-wetting ones are of equal interest.

The results of the study on the thermoindicator film stability for different polymers are presented in the paper.

2. Experiment description. - We have studied several kinds of the films obtained using the technology described in $[4,5]$.

Gelatin and polyvinyl alcohol were employed as hydrophilic polymers. The films were prepared in the following way. $25 \mathrm{ml}$ of $10 \%$ aqueous solution of polyvinyl alcohol was poured into a chemical glass and heated up to $75-80^{\circ} \mathrm{C}$ with continuous stirring. Four grams of liquid-crystalline thermoindicator was molten in another glass. At uniform stirring rate of about 300 revolutions per minute 
liquid crystals were poured slowly into the solution of polyvinyl alcohol. After 30 minutes of stirring the paste was cooled down to the room temperature and cast on the substrate. The reverse side of the films was covered with a black paint to increase the contrast of the colours. Polymethylmethacrylate, polysterene, cellulose acetate have been studied as water-repellent polymers. The mixture of liquid crystals and, for instance, cellulose acetate is dissolved in chloroform (10\% solution). The weight ratio of liquid crystals to cellulose acetate was $1: 1$. Cholesteryl esters were injected into the polymer : mixture A (pelargonate, valerate $50 \%, 50 \%$ ); mixture B (pelargonate $72 \%$, benzoate $10 \%$, oleate $18 \%$ ).

The stability of the films under study was estimated according to the time of the temperature constancy of selective light scattering.

The spectra of selective light scattering were photographed in a set-up the scheme of which is presented in figure 1. A narrow light beam passing monochromator 2 falls on the sample placed inside thermocamera 3. Reflected from the sample the light beam strikes photomultiplier 4 whose signal is sent to the $x$-axis of the two-coordinate recorder 5 . The signal of the thermocouple measuring the temperature at the point of spectrum measurement is fed to the $y$-axis. The accuracy of the temperature measurement is $0.3^{\circ} \mathrm{C}$. A monochromator $\mathrm{UM}-2$ with the dispersion of $40 \AA / \mathrm{mm}$ was employed. The width of the entrance and exit slits was $0.1 \mathrm{~mm}$. All the spectra measurements were performed for a case when the angle between the falling and reflected beams is equal to $15^{\circ}$.

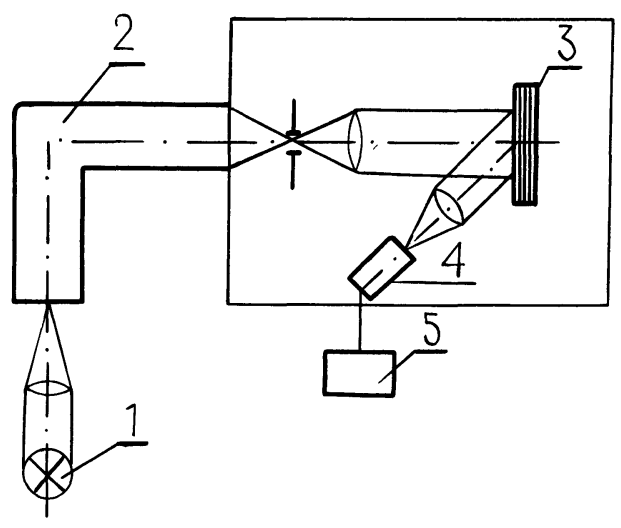

Fig. 1. - Measurement of selective reflection.

3. Experimental results and their discussion. The capsulation of liquid crystals decreases the intensity of the light scattered by the film. Figure 2 presents the measurements of the scattered light $(\lambda=570 \mathrm{HM})$ intensity of pure liquid crystals (mixture A) and liquid crystals dispersed in the polymers. The intensity of the scattered light depends on the polymer type at the same ratio of a polymer

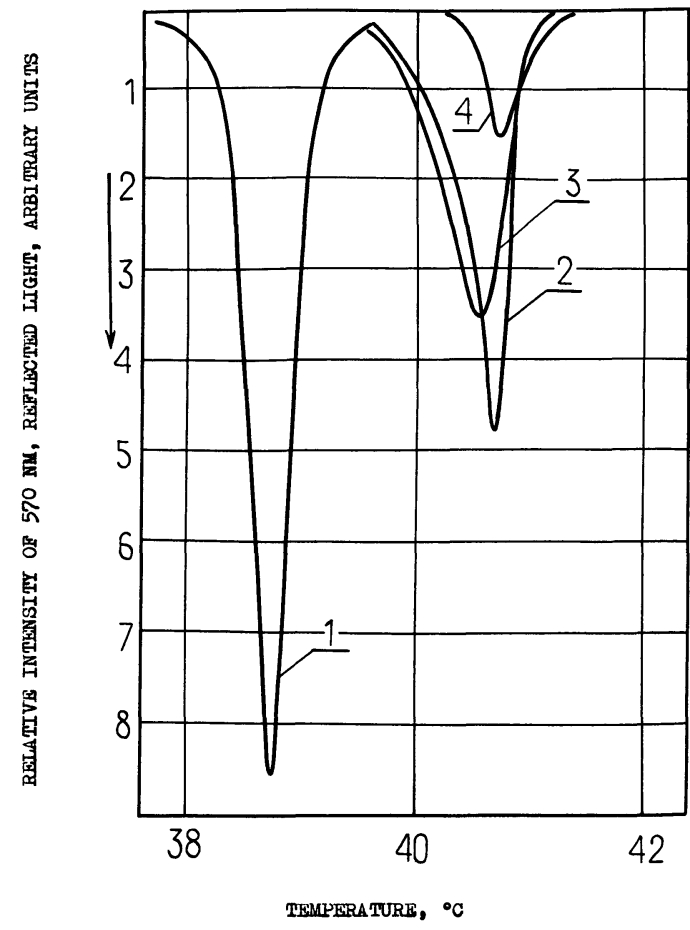

Fig. 2. - Peak reflectance of mixture A : 1) a pure mixture; 2) in cellulose acetate; 3) in polyvinyl alcohol;4) in gelatin.

to a liquid crystal. Such a difference in intensity may be due, firstly, to different absorption of light by polymers and, secondly, to a different structure of the films obtained.

The microphotographs of the cholesteric textures of a pure liquid-crystalline mixture and those of the films on the base of polyvinyl alcohol and ethylcellulose show their different structures (Fig. 3). The films with a more uniform distribution of liquid-crystalline aggregates in the polymer matrix give a larger intensity of the scattered light.

The change of temperature and intensity of the ' scattered light in time by the films on the base of polyvinyl alcohol, cellulose acetate and gelatin will be presented below.

Three sets of samples kept under different conditions have been studied : in the light at room temperature; in the dark at room temperature and radiated by the xenon lamp light. A sharp decrease in intensity of the selectively scattered light and a gradual temperature reduction with time were observed in samples that had been kept in the light and especially in those radiated by the light of xenon lamp (Figs. 4, 5). It is obvious that air oxygen and the ultraviolet radiation exert a strong influence simultaneously on both the liquid crystal capsulated in the polymer and the pure crystal. The change rate of the temperature and the intensity of the selective light scattering depends on the type of polymer in which the liquid crystal is capsulated (Fig. 4, curves 1, 6, 7). The films on the base of polyvinyl alcohol displayed a more stable behaviour. It can be explained by the low gas per- 


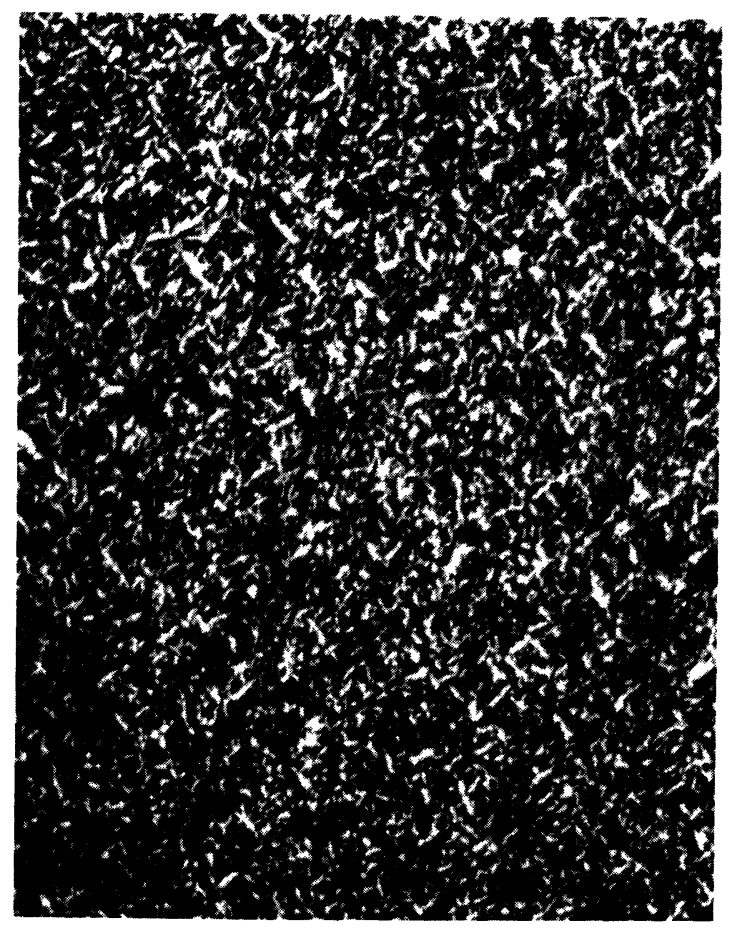

a)

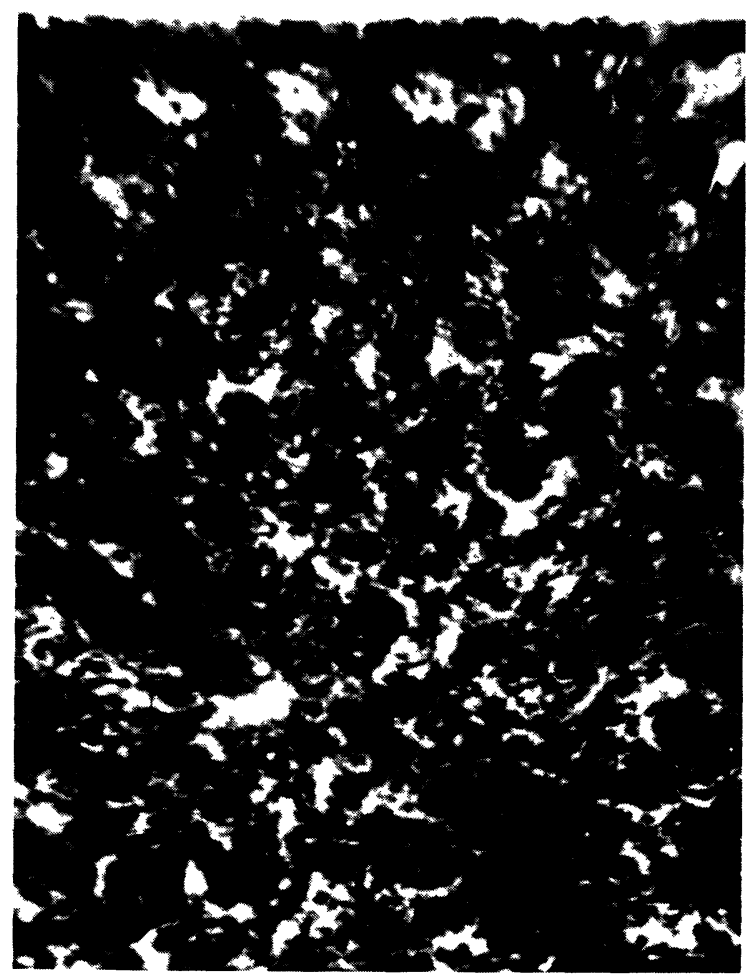

c)

Fig. 3. - Mixture A : 1) a pure mixture. Nicols. mag. $\times 200$; 2) dispersed in cellulose acetate mag. $\times 400 ; 3$ ) dispersed polyvinyl alcohol mag. $\times 400$.

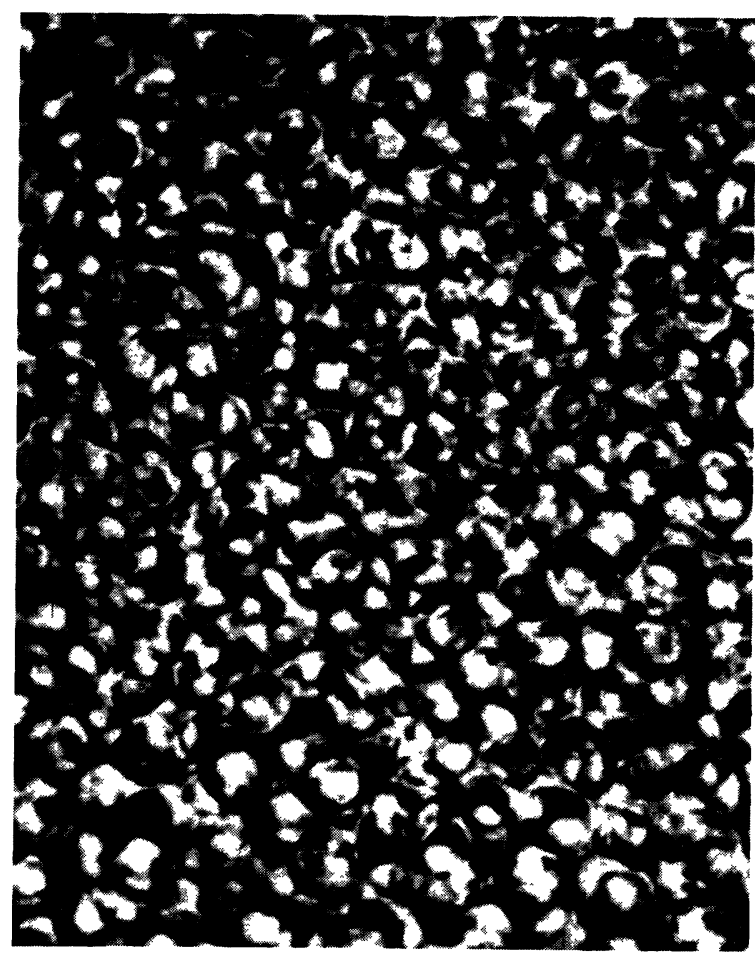

b)

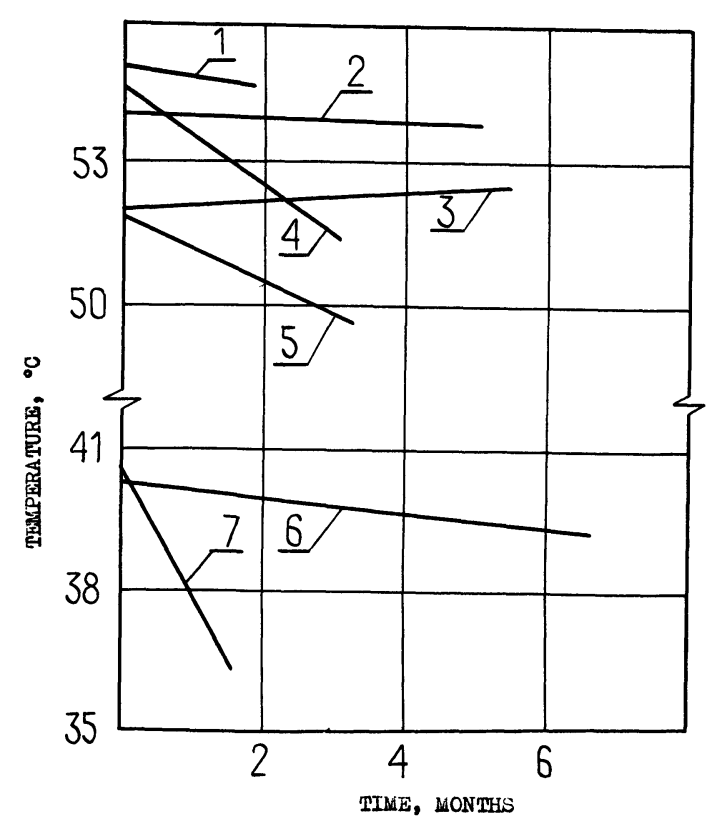

Fig. 4. - Peak reflectance temperature $(570 \mathrm{HM})$ as a function of time. Mixture B + cellulose acetate -1 ; mixture B + cellulose acetate $+6 \%$ stabilizers (1)-(4) to the weight of liquid crystals : (1) -2 ; (2) -3 ; (4) -4 ; (3) -5 . Mixture $A+$ polyvinyl alcohol - 6; Mixture A + gelatin - 7 . 


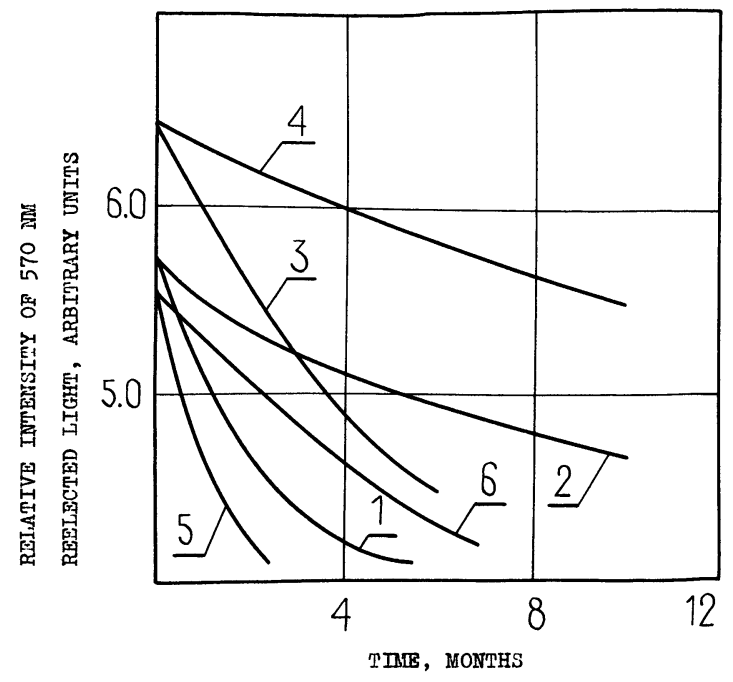

Fig. 5. - Peak reflectance intensity as a function of time. Mixture $\mathrm{B}+$ cellulose acetate $+6 \%$ stabilizer : stabilizer (1) in the light -1 , in the dark -2 ; stabilizer (2) in the light -3 , in the dark -4 ; stabilizer (3) in the light -5 , in the dark -6 .

meability of the polymer in question, which is associated with its compact and regulated structure in comparison with other polymers [6].

We have tried to increase the working period of the films on the base of cellulose acetate (with greater gas permeability) by adding light stabilizers and antioxidants. The following stabilizers were employed : the phenolic compounds : 2,6-di-terbutylphenol (1); pentamethylphenol (2); aromatic oxycompounds (2-hydroxy-benzophenone derivatives) : 2-oxy-4-methyoxy-2', 3', 4', 5', 6'-pentafluorinebenzophenone (3); 1-(3-oxy-4-benzoylphenoxy)-34-(2-oxybenzoyl)-phenoxy-propanol-2 (4); 2-oxy-4 methoxyoctafluorinebenzophenone (5); pentanominal heterocycle compounds (derivatives of benzotriazol) : 2-(2-oxy-5-methylphenyl)-benzotriazol (6), 2 - 2 - oxy - 3' - ter - butyl - 5' - methyl) - 6 - chlorbenzotriazol (7).

From the above listed compounds the phenolic kind has proved to be the most important class of the antioxidants widely adopted for the stabilization of polymer films and oil products [7]. It is well-known that compounds of this kind are also of positive effect for the stabilization of liquid crystals $[8,9]$. The other compounds, in particular, the derivatives of 2-hydroxy-benzophenone are classic light stabilizers.

The sets of samples with stabilizing agents were kept for a year both in the light and in the dark.

The light stabilizers (Fig. 4, curves 4, 5) and especially the antioxidants (Fig. 4, curves 2,3 ) present in the films increase the working period of these films as compared with the control sample. The samples with the antioxidants that were kept in the dark (Fig. 5, curves 2, 4) have shown lesser changes in temperature and in intensity of selectively scattered light.

The above data on the behaviour of the films with the added stabilizers kept in the dark and in the light enable us to assume that the ageing process of liquid crystals dispersed in polymers is mainly induced by oxidizing processes.

4. Conclusion. - The stability of cholesteric liquid crystals dispersed in a polymer matrix depends upon the polymer gas permeability. The injection of antioxydants of the phenolic kind into a polymer containing a liquid crystal increases essentially the time of their stable operation.

\section{References}

[1] Scala, L. C., Dixon, G. D., J. Mol. Cryst. Liquid Crystals 7 (1969).

[2] Zharkova, G. M., Khachaturyan, V. M., Gazodinamika $i$ Phizicheskaya Kinetika (ITiPM, Novosibirsk) 1974.

[3] French Patent No. 2051423.

[4] Dixon, G. D., Meier, J. F., J. Mol. Cryst. Liquid Crystals 37 (1976) 233.

[5] Shevchuk, S. V., Makhotilo, A. P., Tishchenko, V. G., Kholestericheskiye zhidkiye kristally (Novosibirsk) 1976, 67.
[6] Ushakov, S. N., Polivinilovyi, spirt i ego proizvodnyje (Izd. Akademii Nauk SSSR) 1960, t. 1, 2.

[7] FoIGT, I., Stabilizatsiya sinteticheskikh polimerov protiv dejstvija sveta i tepla (Izd. « Khimiya ») 1972.

[8] Chistyakov, I. G., Gorina, I. I., Rubtsova, M. Yu. Kristallographiya 22 (1977) 334.

[9] Japan Patent No. 7501, 082. 